\title{
Critical Factors Influencing Pre-Service Teachers' Use of the Internet of Things (IoT) in Classrooms
}

\author{
https://doi.org/10.3991/ijim.v16i04.27007
}

\author{
Ahlam Mohammed Al-Abdullatif ${ }^{1(凶)}$, Amany Ahmed Al-Dokhny², \\ Amr Mohammed Drwish ${ }^{3}$
}

${ }^{1}$ Curriculum and Instruction Department, King Faisal University, Alahssa, Saudi Arabia ${ }^{2}$ Faculty of Specific Education, Ain Shams University, Cairo, Egypt

${ }^{3}$ Faculty of Education, Helwan University, Cairo, Egypt

aalabdullateef@kfu.edu.sa

\begin{abstract}
This study aimed to explore the factors influencing pre-service teachers' decisions to use the Internet of Things (IoT) in a classroom as a digital system to enhance teaching and learning. The technology acceptance model (TAM) was used to investigate the effects of using the IoT in an e-learning environment on pre-service teachers' perceived usefulness, ease of use, attitudes toward using IoT, and the influence of such attitudes on students' behavior. Forty-seven final-year pre-service teachers were selected to participate by purposeful sampling. A quantitative approach via regression analysis was taken to analyze the collected data. The results showed that the TAM-related factors of the IoT's perceived usefulness and ease of use significantly contributed to pre-service teachers' attitudes toward using IoT in classrooms. However, their attitude toward the IoT was not influential in their intention to use it. On the other hand, its perceived usefulness was the most critical factor in pre-service participants' intention to use or continue to use the IoT in the future. Accordingly, several pedagogical implications for the design and development of teacher preparation programs are discussed. Recommendations for future work are suggested as a result of this study.
\end{abstract}

Keywords-internet of things, IoT, critical factors, pre-service teachers, e-learning, technology acceptance model

\section{Introduction}

The Internet of Things (IoT) is the next generation of Internet technology that uses smart devices to connect the physical world and cyberspace [1]. IoT systems are becoming more pervasive, and their widespread adoption has had a significant impact on all aspects of life for billions of people in just a few years [2]. The Global Standards Initiative on the Internet of Things defines the IoT as "the global infrastructure for the information society that can facilitate interconnecting all types of objects, such as physical and virtual things based on the presented telecommunication protocols and 
technologies" [3] (p. 914). The IoT is considered an automation and analytics system as it uses networks, sensors, big data, and artificial intelligence technology to create flawless service systems [4]. IoT pervasiveness facilitates daily tasks, enriches people's interactions with their surroundings, and enhances social relationships with other people and items [5].

The IoT transforms and reshapes our children's digital and technical world [6]. By 2025, more than 75 billion IoT-enabled devices will be installed around the globe [7]. The IoT quickly changes the traditional education system into more flexible, adaptive, and efficient [3]. Therefore, the influence of IoT technologies on our educational systems is inevitable. There is significant potential for IoT technology to improve the process of teaching and learning and make "anytime, anywhere" a reality [8]. However, the educational use of the IoT is still in its infancy [3], and only a limited number of articles have focused on applying the IoT in education, particularly within the context of developing countries [9]. For example, in a recent systematic review, [10] observed that the acceptance and potential usage of the IoT in education are still rare, especially in developing countries (e.g., Saudi Arabia). This leaves plenty of room for researchers to study the issues impacting the educational applications of IoT, particularly in developing countries. Research in this field is scarce and relatively new. To digitally transform Saudi preservice teachers, there is an urgent need to identify their readiness, technological acceptance, and intention to use technologies (e.g., IoT) in their future classrooms. Therefore, the current study aims to contribute to the existing literature by addressing this need.

Since the presence of the IoT cannot be overlooked [11], training pre-service teachers to integrate emergent technology is vital [12] [13]. However, to prepare them, it is necessary to detect the factors influencing their usage intention of IoT technology in teaching and learning environments. This study examines the critical factors influencing pre-service teachers' intentions to use the IoT in their classrooms by establishing what factors contribute to their behavioral intentions to use IoT technologies in their future teaching and learning. The findings of this research study may advance our understanding of the critical factors influencing pre-service teachers' intentions to use IoT and, therefore, their actual use of IoT in their future professions. The current study's findings may suggest several pedagogical implications regarding designing, developing, and evaluating teacher preparation programs to include IoT technologies in design and practice.

The remainder of this study is organized as follows. The second section discusses the literature review, and the theoretical framework and hypothesis development are presented in the third section. The fourth section describes the methodology (including the sample and context, instrument, data collection, and analysis). The results of this study are presented in the fifth section. Discussions and implications are outlined in the sixth section, followed by the conclusions and limitations in the seventh section.

\section{$2 \quad$ Literature review}

\subsection{The IoT in education}

Integrating the IoT into the realm of education is rapidly increasing and is beneficial in connecting and educating learners [10] [14]. Students can learn faster and teach 
more efficiently by implementing the IoT in any educational setting [14] [15]. Enabling interaction with learners in a unique and individualized way has been identified as one of the critical benefits of the IoT in education. Students and instructors can also better engage with one another and with physical and virtual items in the classroom [8] [11]. Consequently, IoT-based learning environments can significantly influence students' and instructors' tasks and activities [3].

Several studies in the literature have acknowledged the positive influence of integrating the IoT in an educational environment on teaching and learning performance. For example, [16] conducted an experimental study with 50 students enrolled in an engineering course and found that the IoT was used to support the process of teaching and enhance student academic achievement. They found that, through the IoT, natural objects can be used as learning resources, as they can be linked to virtual objects, which provides more information and aids meaningful learning. In another example, [17] designed and implemented an experimental distance teaching platform for architecture based on the IoT. The results revealed that IoT technology might increase students' academic achievement and improve teachers' ability to deliver their lessons. An IoT-based teaching management system created by [18] assisted teachers in tracking student attendance and increasing enthusiasm for studying; it was found to influence students' learning processes for higher education favorably. Furthermore, [9] conducted a study with 244 students and four teachers in Thailand examining the impact of sensor-based IoT on children's engagement in learning. The findings showed that the students who used sensor-based IoT to study had considerably better-learning outcomes and engagement than those who did not.

More recently, [19] conducted a study to investigate the possibilities of Google Lens as an IoT tool in biology classes in Ukrainian schools. They found that Google Lens had outstanding outcomes and should be used in teaching. Furthermore, [20] conducted a mixed-method study with 56 students from three schools in Malaysia to investigate the effectiveness of Voca-Lens and found it had a positive impact on promoting students' motivation and learning outcomes. Other recent studies on the positive influence of IoT-based learning environments on students' learning outcomes include improving creativity in learning [21], enhancing achievements in software design and production [22], and improving language competency [23].

\subsection{Pre-service teachers in the Saudi context}

Technology is a significant facilitator and driver of Saudi Arabia's future development [24]. Therefore, teachers' technical skills are highly valued, and technological integration in the teaching-learning process has increasingly become a significant component of the Saudi educational system [25]. As a result, Saudi teaching standards presently demand that Saudi teachers at all educational levels be competent in digital technologies to improve and transform teaching and learning [26]. Teacher preparation programs (pre-service training) are considered the cornerstone of teacher education because they ensure that novice teachers are competent for their future classrooms [27].

Colleges and universities should provide pre-service teachers with high digital literacy training [28]. For pre-service teachers to be more responsive to the challenges and opportunities of rapid technological integration, education preparation programs must 
be revised holistically across all topic areas [29]. When investigating the technological acceptance of the IoT in mathematics pre-service teachers, [30] stated the necessity of developing programs in faculties of education to prepare them. Other studies aimed at understanding pre-service teachers' perspectives of implementing the IoT in teaching and learning found that teachers lack adequate preparation for using IoT technology in their classrooms [31] [32]. Thus, this study aims to investigate the intended use of the IoT based on the technology acceptance model (TAM), targeting pre-service teachers in Saudi Arabia. This investigation is conducted using the TAM, outlined in the next section.

\section{Theoretical framework and hypothesis}

The TAM model was initially proposed by [33] and is one of the most commonly recognized frameworks for understanding individuals' attitudes toward technology. [33] proposed the TAM to anticipate or clarify the factors that determined an individual's usage of any information technology (IT) system [34] [35]. In the TAM (shown in Figure 1), users' acceptance of an IT system is influenced by their behavioral intention to use the system [36]. According to the TAM, the acceptance and rejection of any technological application are influenced mainly by two main factors: perceived ease of use and perceived usefulness [37]. Perceived usefulness is defined as "the degree to which a person believes that using a particular system would enhance his or her job performance," whereas perceived ease of use refers to "the degree to which a person believes that using a particular system would be free of effort" [33] (p. 320). In other words, the degree of user acceptance of the features and functions of the technology extensively and fundamentally affects the degree of readiness and willingness to use such technology [38].

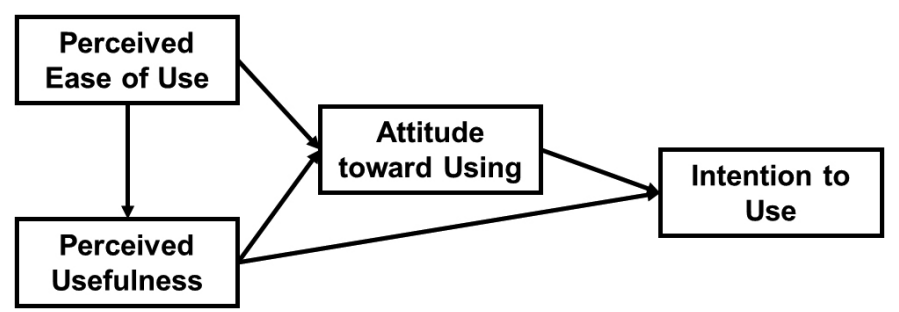

Fig. 1. The TAM [33]

Both perceived usefulness and ease of use positively influence users' attitudes toward utilizing the technology and their intention, which, in turn, affects the actual usage of technology [39]. Attitude refers to a "user's evaluation regarding the usage of the system" [36] (p. 194). According to [40], TAM factors "appear to be able to account for 40 percent to 50 percent of user acceptance" (p. 152). By adopting the TAM, this study attempts to elucidate what influences pre-service teachers to accept or reject using the IoT in a learning environment based on the factors of perceived usefulness and perceived ease of use. 
In summary, both perceived usefulness and perceived ease of use were found to positively impact behavioral intention toward using a system, and perceived ease of use was reported to impact perceived usefulness [41] positively. Therefore, the following research questions and hypotheses (Hs) were formulated based on the four TAM factors of technology use: perceived ease of use, perceived usefulness, user attitude, and a user's behavioral intention to use technology.

Research question 1: What is the relationship between pre-service teachers' perceptions of IoT ease of use and their perceptions of its usefulness?

H1: There is a significant relationship between pre-service teachers' perceptions of IoT ease of use and its usefulness.

Research question 2: What is the relationship between pre-service teachers' perceptions of IoT ease of use and their attitude toward its use?

$\mathrm{H} 2$ : There is a significant relationship between pre-service teachers' perceptions of IoT ease of use and their attitude toward its use.

Research question 3: What is the relationship between pre-service teachers' perceptions of IoT usefulness and their attitude toward its use?

H3: There is a significant relationship between pre-service teachers' perceptions of IoT usefulness and their attitude toward its use.

Research question 4: What is the relationship between pre-service teachers' perceptions of IoT usefulness and their intention to use it?

H4: There is a significant relationship between pre-service teachers' perceptions of IoT usefulness and their intention to use it.

Research question 5: What is the relationship between pre-service teachers' attitudes toward using IoT and their intention to use it?

H5: There is a significant relationship between pre-service teachers' attitudes toward using IoT and their intention.

\section{$4 \quad$ Methodology}

A descriptive research design using a quantitative approach was implemented in this study to examine the TAM factors that determine pre-service teachers' decision to use (adopt) the IoT for teaching and learning in their future classrooms.

\subsection{Sample and context}

To attain the aim of this study, a purposive sample [42] was used with a total of 47 pre-service teachers from the faculty of education, including final-year undergraduate male and female students studying a Bachelor of Computer Teacher program. Participants were enrolled in an Instructional Software Design course and were required to 
complete a set of assignments related to the topic of the weekly lecture over 14 weeks. In each of these assignments, the students were asked to select one IoT application (e.g., Google Lens, Goggle Assistant, etc.) and utilize its functions for several purposes, such as researching, reporting, or obtaining practical design skills. For example, students were asked to perform direct searches (typing into the search engine via the application), translate, or read specific text on the display screen (scanning a barcode or recognizing text through the application). The assignments were consistent with the course outcomes in equipping the students with the skills and competencies necessary for their future profession as a teacher.

\subsection{Instrument}

A survey questionnaire was employed in this study to investigate pre-service teachers' perceptions of the use of the IoT in the classroom. The self-report questionnaire was adopted from Davis [33], based on the four validated constructs of perceived ease of use, perceived usefulness, user's attitude, and IoT intention to use. A 5-point Likert scale (from $1=$ 'strongly agree' to $5=$ 'strongly disagree') was used to measure all survey items. Table 1 shows the survey constructs and items.

Table 1. Survey instrument (adapted from [33] to the context of this study)

\begin{tabular}{|l|l|}
\hline \multicolumn{1}{|c|}{ Constructs } & \multicolumn{1}{c|}{ Items } \\
\hline \multirow{5}{*}{ Perceived usefulness (6 items) } & Accomplish tasks \\
\cline { 2 - 2 } & Improve learning performance \\
\cline { 2 - 2 } & Increase productivity \\
\cline { 2 - 2 } & Make learning easier \\
\cline { 2 - 2 } Perceived ease of use (6 items) & Useful for learning \\
\cline { 2 - 2 } & Enhance learning effectiveness \\
\hline \multirow{5}{*}{ Intention to use (3 items) } & Easy to learn \\
\cline { 2 - 2 } & Easy to apply \\
\cline { 2 - 2 } & Easy to understand \\
\cline { 2 - 2 } & Easy to become skillful at using \\
\cline { 2 - 2 } & Make learning more flexible. \\
\cline { 2 - 2 } & Easy to use \\
\hline \multirow{5}{*}{ Attitude toward using (4 items) } & Good idea \\
\cline { 2 - 2 } & Interesting to learn \\
\cline { 2 - 2 } & Fun to learn \\
\cline { 2 - 2 } & Trending in education \\
\hline & Predict to its use in the future \\
\cline { 2 - 2 } & Intend to it use the future \\
\cline { 2 - 2 } & Plan to use it in the future \\
\hline
\end{tabular}




\subsection{Data collection and analysis}

The data was collected during the first semester of the 2019/2020 academic year from an online survey of pre-service teachers to support the investigation of their perceptions of perceived ease of use and perceived usefulness of the IoT in classrooms and their attitudes toward its use. These relationships were then examined in terms of their association to pre-service teachers' intentions to use IoT applications in classrooms. In this study, regression analysis was used to deduce the associations between the independent and dependent variables. Three associations were examined: (1) the association between perceived IoT ease of use and usefulness; (2) the association among perceived IoT ease of use, usefulness, and attitudes; (3) the association among IoT usefulness, attitude, and intention to use IoT.

Regression analysis was implemented to detect which factors (independent variables) were predictors of (or related to) the pre-service participants' intention to use the IoT (dependent variable/outcome). Two steps of analysis were conducted: (1) data were screened using Cronbach's alpha for reliability, and Pearson's correlations between the independent and dependent variables and descriptive statistics for the study variables (means and standard deviations) were conducted; (2) once a regression model was created (three relationships with three hypotheses), the model's goodness of fit was confirmed. The statistical significance of estimated parameters, such as $\mathrm{R}^{2}$, F-test of the overall fit, and t-tests of individual parameters, were analyzed to identify the coefficient and relationships among variables. To test the five hypotheses, one simple linear regression and two multiple linear regressions were performed. Table 2 shows the dependent and independent variables of the straightforward regression $(\mathrm{H} 1)$ and the two multiple linear regressions (H2-H5).

Table 2. Hypotheses and their dependent and independent variables

\begin{tabular}{|l|c|c|}
\hline \multicolumn{1}{|c|}{ Dependent Variable } & Independent Variable & Hypotheses \\
\hline Perceived usefulness & Perceived ease of use & $\mathrm{H} 1$ \\
\hline \multirow{2}{*}{ Attitude } & Perceived ease of use & $\mathrm{H} 2$ \\
\cline { 2 - 3 } & Perceived usefulness & $\mathrm{H} 3$ \\
\hline \multirow{2}{*}{ Intention of use } & Perceived usefulness & $\mathrm{H} 4$ \\
\cline { 2 - 3 } & Attitude & $\mathrm{H} 5$ \\
\hline
\end{tabular}

The assumptions of multiple linear regression indicated by [43] were examined, and all were fulfilled, including linearity, the dependence of residuals, homoscedasticity, and the normality of residuals distribution. Additionally, multicollinearity was checked using the variance inflation factor (VIF), tolerance statistics, and correlation coefficient between independent variables (predictors) above 0.8 ; multicollinearity was not an issue. A p-value of less than 0.05 showed a significant level for all tests.

\section{$5 \quad$ Results}

The reliability and validity of the survey items using Cronbach's alpha were established first. The independent and dependent variables were then calculated using 
Pearson's correlation, and descriptive analyses of all variables were presented. Subsequently, the simple regression results and two multiple linear regressions were provided.

\subsection{Reliability and validity analysis}

The reliability of the survey consisting of four measures was calculated using Cronbach's alpha coefficient (if an item was deleted) and correlation coefficients (item-total correlation) to measure the internal consistency between the items of each construct (variable). The results in Table 3 indicate that all correlation coefficients with the total degree of the variable (item-total correlation) were statistically significant $(\alpha=0.01)$, which indicates the internal consistency and reliability of all of the items in the survey. The overall Cronbach's alpha of the four study variables (perceived ease of use, perceived usefulness, attitude, and intention to use) ranged from 0.844 to 0.893 , which is considered a high level of reliability [44]. Correlation coefficients of all items (corrected item-total correlation) were statistically significant at the 0.01 level, which showed the validity of the instrument's items.

Table 3. Reliability and validity coefficients of the survey

\begin{tabular}{|c|c|c|c|c|c|c|}
\hline Constructs & Items & M (SD) & $\begin{array}{l}\text { Cronbach's } \\
\text { Alpha (if Item } \\
\text { Deleted) }\end{array}$ & $\begin{array}{l}\text { Item-Total } \\
\text { Correlation }\end{array}$ & $\begin{array}{l}\text { Corrected } \\
\text { Item-Total } \\
\text { Correlation }\end{array}$ & $\begin{array}{c}\text { Cronbach's } \\
\text { Alpha }\end{array}$ \\
\hline \multirow{6}{*}{$\begin{array}{l}\text { Perceived ease } \\
\text { of use } \\
\text { (6) items }\end{array}$} & PEU1 & \multirow[t]{6}{*}{3.99 (.69) } & .796 & $.849 *$ & $.741 *$ & \multirow[t]{6}{*}{.854} \\
\hline & PEU2 & & .817 & $.753 *$ & $.652 *$ & \\
\hline & PEU3 & & .800 & $.823^{*}$ & $.733^{*}$ & \\
\hline & PEU4 & & .813 & $.780 *$ & $.659 *$ & \\
\hline & PEU5 & & .807 & $.660 *$ & $.480^{*}$ & \\
\hline & PEU6 & & .803 & $.814^{*}$ & $.707^{*}$ & \\
\hline \multirow{6}{*}{$\begin{array}{l}\text { Perceived } \\
\text { usefulness } \\
\text { (6) items }\end{array}$} & PU1 & \multirow[t]{6}{*}{$3.74(.76)$} & .893 & $.734 *$ & $.599 *$ & \multirow[t]{6}{*}{.893} \\
\hline & PU2 & & .866 & $.844^{*}$ & $.774 *$ & \\
\hline & PU3 & & .880 & $.786^{*}$ & $.678^{*}$ & \\
\hline & PU4 & & .853 & $.897^{*}$ & $.839 *$ & \\
\hline & PU5 & & .869 & $.830 *$ & $.747^{*}$ & \\
\hline & PU6 & & .881 & $.765^{*}$ & $.667^{*}$ & \\
\hline \multirow{4}{*}{$\begin{array}{l}\text { Attitude } \\
\text { toward use } \\
\text { (4) items }\end{array}$} & AU1 & \multirow[t]{4}{*}{$3.79(.74)$} & .856 & $.742 *$ & $.549^{*}$ & \multirow[t]{4}{*}{.844} \\
\hline & AU2 & & .774 & $.864 *$ & $.744^{*}$ & \\
\hline & AU3 & & .748 & $.899 *$ & $.794^{*}$ & \\
\hline & AU4 & & .816 & $.795^{*}$ & $.646^{*}$ & \\
\hline \multirow{3}{*}{$\begin{array}{l}\text { Intention to use } \\
\text { (3) items }\end{array}$} & IU1 & \multirow[t]{3}{*}{$3.74(.72)$} & .905 & $.809^{*}$ & $.626^{*}$ & \multirow[t]{3}{*}{.863} \\
\hline & IU2 & & .711 & $.937^{*}$ & $.837^{*}$ & \\
\hline & IU3 & & .772 & $.906^{*}$ & $.777^{*}$ & \\
\hline
\end{tabular}

Note: *Correlation is significant at the 0.01 level. 


\subsection{Correlation and descriptive analysis}

As shown in Table 3, the mean of four study constructs ranged from 3.74 to 3.99, demonstrating that pre-service teacher participants' perceptions of the IoT were slightly high in terms of these four factors.

Table 4. Correlations between independent and dependent variables

\begin{tabular}{|l|c|c|c|c|}
\hline Hypotheses & Dependent Variable & Independent Variable & $\begin{array}{c}\text { Pearson } \\
\text { Correlation }\end{array}$ & $\boldsymbol{p}$-Value \\
\hline H1 & Perceived usefulness & Perceived ease of use & .690 & $.000 *$ \\
\hline H2 & Attitude & Perceived ease of use & .742 & $.000 *$ \\
\hline H3 & Attitude & Perceived usefulness & .668 & $.000 *$ \\
\hline H4 & Intention of use & Perceived usefulness & .656 & $.000 *$ \\
\hline H5 & Intention of use & Attitude & .545 & $.000^{*}$ \\
\hline
\end{tabular}

Note: *Correlation is significant at the 0.01 level.

Before regression analysis, for each hypothesis, Pearson's correlation coefficient was calculated between the dependent and independent variables. All correlations (shown in Table 4) were statistically significant and positive between every pair of variables: perceived ease of use and perceived usefulness $(\mathrm{r}=.690, \mathrm{p}<.001)$, perceived ease of use and attitude $(\mathrm{r}=.742, \mathrm{p}<.001)$, perceived usefulness and attitude $(\mathrm{r}=.668, \mathrm{p}<.001)$, the intention of use and perceived usefulness $(\mathrm{r}=.656, \mathrm{p}<.001)$, and intention of use and attitude $(\mathrm{r}=.545, \mathrm{p}<.001)$.

\subsection{Simple regression analysis}

To answer research question 1: "What is the relationship between pre-service teachers' perceptions of IoT ease of use and their perceptions of its usefulness?" a simple regression analysis was conducted to test hypothesis 1 . The result is presented in Table 5 and shows that the value of $\mathrm{R}^{2}$ is .476 , which indicates that perceived ease of use accounts for $47.6 \%$ of the variation in perceived usefulness.

Table 5. Results of the simple regression analysis

\begin{tabular}{|c|c|c|c|c|c|c|}
\hline \multirow[t]{2}{*}{ Model } & \multicolumn{2}{|c|}{$\begin{array}{l}\text { Unstandardized } \\
\text { Coefficients }\end{array}$} & \multirow{2}{*}{$\begin{array}{c}\begin{array}{c}\text { Standardized } \\
\text { Coefficients }\end{array} \\
\text { Beta }\end{array}$} & \multirow[t]{2}{*}{$\mathbf{t}$} & \multirow[t]{2}{*}{$p$-Value } & \multirow[t]{2}{*}{$\mathbf{R}^{2}$} \\
\hline & B & Std. Error & & & & \\
\hline $\begin{array}{l}\text { Perceived ease } \\
\text { of use }\end{array}$ & .753 & .118 & .690 & 6.400 & $.000 *$ & .476 \\
\hline
\end{tabular}

Note: *Indicates significance at the .05 level.

A statistically significant and positive relationship was detected between perceived usefulness and perceived ease of use $(B e t a=.690, p=.000)$, which means that increasing one unit of perceived ease of use will increase .690 units of perceived usefulness. Therefore, hypothesis 1 was supported, indicating that pre-service teachers' perceptions 
of the IoT usefulness are positively and significantly affected by their perceptions of ease of use.

\subsection{Multiple linear regression analysis}

In this study, two multiple linear regressions were performed. The first was conducted to answer research question 2: "What is the relationship between pre-service teachers' perceptions of IoT ease of use and their attitude toward its use?", and therefore test hypothesis 2 . In addition, it was conducted to answer research question 3 : "what is the relationship between pre-service teachers' perceptions of IoT usefulness and their attitude toward its use?" and therefore test hypothesis 3; the results are presented in Table 6. Overall, the value of $\mathrm{R}^{2}$ is .597 , which indicates that the model accounts for $59.7 \%$ of the variation in attitude. A statistically significant positive relationship was found between perceived ease of use and attitude (Beta=.536, $\mathrm{p}=.029$ ) and between perceived usefulness and attitude $(\operatorname{Beta}=.299, \mathrm{p}=.000)$. This means that perceived ease of use and usefulness have significantly and proportionally influenced participants' attitudes; however, perceived ease of use had a more substantial influence (.536) than perceived usefulness (.299). Therefore, there was enough evidence to support hypotheses 2 and 3. In particular, pre-service teachers' attitudes toward the use of the IoT in classrooms is positively and significantly affected by their perceptions of its ease of use (hypothesis 2), and pre-service teachers' attitudes toward using the IoT in classrooms is positively and significantly affected by their perceptions of its usefulness (hypothesis 3).

Table 6. Results of the multiple regression analysis (attitude as dependent variable)

\begin{tabular}{|c|c|c|c|c|c|c|}
\hline \multirow[t]{2}{*}{ Model } & \multicolumn{2}{|c|}{$\begin{array}{c}\text { Unstandardized } \\
\text { Coefficients }\end{array}$} & \multirow{2}{*}{$\begin{array}{c}\text { Standardized } \\
\text { Coefficients } \\
\text { Beta }\end{array}$} & \multirow[t]{2}{*}{$\mathbf{t}$} & \multirow[t]{2}{*}{$p$-Value } & \multirow[t]{2}{*}{$\mathbf{R}^{2}$} \\
\hline & B & Std. Error & & & & \\
\hline $\begin{array}{l}\text { Perceived ease } \\
\text { of use }\end{array}$ & .569 & .141 & .536 & 4.049 & $.029 *$ & .597 \\
\hline $\begin{array}{l}\text { Perceived } \\
\text { usefulness }\end{array}$ & .291 & .129 & .299 & 2.257 & $.000 *$ & \\
\hline
\end{tabular}

Note: *Indicates significance at the .05 level.

The second multiple linear regression analysis was performed to answer research question 4: "What is the relationship between pre-service teachers' perceptions of IoT usefulness and their intention to use it?" and therefore test hypothesis 4 . In addition, it was conducted to answer research question 5: "What is the relationship between pre-service teachers' attitudes toward using IoT and their intention to use it?" and, therefore, to test hypothesis 5, the results are presented in Table 7. Overall, the value of $\mathrm{R}^{2}$ is .451 , which indicates that the model accounts for $45.1 \%$ of the variation in the intention to use. A statistically significant positive relationship was found between the intention to use and perceived usefulness $(B e t a=.528, p=.001)$, but the relationship between intention and attitude was not statistically significant (Beta=.192, $\mathrm{p}=.207)$. This means that intention to use was proportionally and significantly influenced by perceived usefulness but not attitude toward it. Therefore, hypothesis 4 was supported, 
but there was insufficient evidence to support hypothesis 5. In particular, pre-service teachers' intentions to use the IoT in classrooms were positively and significantly affected by their perceptions of its usefulness (hypothesis 4). However, pre-service teachers' intentions to use the IoT in classrooms were not significantly affected by their attitudes toward its use (hypothesis 5).

Table 7. Results of multiple regression analysis (to use as the dependent variable)

\begin{tabular}{|l|c|c|c|c|c|c|}
\hline \multirow{2}{*}{ Model } & \multicolumn{2}{|c|}{$\begin{array}{c}\text { Unstandardized } \\
\text { Coefficients }\end{array}$} & $\begin{array}{c}\text { Standardized } \\
\text { Coefficients }\end{array}$ & \multirow{2}{*}{$\mathbf{t}$} & $\boldsymbol{p}$-Value & \multirow{2}{*}{$\mathbf{R}^{2}$} \\
\cline { 2 - 6 } & $\mathbf{B}$ & Std. Error & Beta & & & \\
\hline $\begin{array}{l}\text { Perceived } \\
\text { usefulness }\end{array}$ & .506 & .144 & .528 & 3.515 & $.001 *$ & .451 \\
\hline Attitude & .189 & .148 & .192 & 1.281 & .207 & \\
\hline
\end{tabular}

Note: *Indicates significance at the .05 level.

The summary results of all three regressions are shown in Figure 2. For all test results, $\mathrm{p}$-value $<.05$, and the arrows represent the coefficient (path analysis).

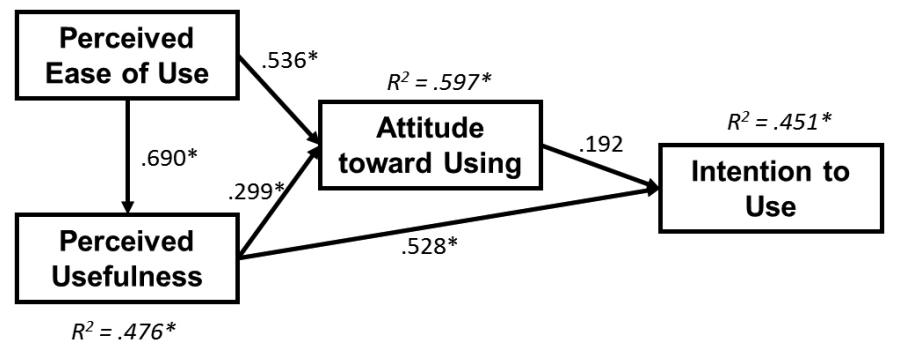

Fig. 2. Summary of research results

\section{Discussion and implications}

This research highlights that pre-service teachers' intentions to use IoT technology were positively and significantly affected by their perceptions of its usefulness. The main factor influencing the participants' decisions to use IoT technology in their future classrooms was how it supported the teaching-learning process. This result is supported by related literature emphasizing the pedagogical practices enhanced by integrating IoT technology for teachers. Such practices include increasing engagement and interactions [5], creating a more flexible and efficient learning environment [14], and promoting students' motivation to achieve their learning outcomes [20].

Perceived usefulness was positively and significantly influenced by perceived IoT ease of use among the study's participants. This result affirms those reported by [34] and [35] in their investigations of teachers' intentions to use technologies (e.g., multimedia and smartphone clicker apps). Additionally, the TAM literature supports the results [33], wherein perceived usefulness and ease of use are two critical factors that positively or negatively impact a user's behavioral intention to adopt the technology. 
This result may be because participants were final-year students majoring in an educational technology degree; therefore, they dealt with different technological applications in their courses and might not have had any difficulties utilizing several IoT applications in their learning tasks and activities. This confirms the suggestion by [45] that a user's level of concern with technology usefulness is positively associated with their degree of familiarity using it.

The results also indicate that the pre-service teacher participants' attitudes were positively determined by perceived usefulness and perceived ease of use. These findings are consistent with previous research, i.e., [45] [46]. According to [36], when using a particular technology, the level of an individual's confidence plays a significant role in their attitude toward the adoption of such technology. With this in mind, the new experiences of participants with the IoT applications in this study might decrease confidence in using the IoT. Another reason, according to [47], might be attributed to the insignificant role of attitude as a mediating factor between users' perceived usefulness, ease of use, and behavioral intention.

In summary, a key finding from the data analysis is that pre-service teacher participants are generally influenced by their perceptions of the usefulness of IoT technology as participants usually tend to choose or use any digital application based on the benefit (usefulness) sought from it. Therefore, based on this study's findings, the perceived usefulness of the IoT is the most critical factor in the pre-service participants' intention to use it or continue to do so in the future. A crucial pedagogical implication for such a result is that university instructors and course developers should consider including more IoT technologies in the course syllabi of teacher preparation programs. Pre-service teachers enrolled in such programs should become familiar with and experienced utilizing different IoT applications for learning tasks and activities. To enhance the usefulness of the IoT, instructors should make it easier to apply IoT technology and facilitate students to build material, perform tasks, and create activities. The advantages of using the IoT in facilitating the teaching-learning process, such as flexibility, adaptability, efficiency, and enhancing academic performance [48], should be emphasized so that students' attitudes toward using the IoT in future classrooms are positive and intend to use.

Additionally, pre-service training in integrating the IoT should be given more attention by instructors and program developers in education colleges to ensure that newer teachers are competent for their future professions. Training is a determining factor in teachers' success, particularly when considering new and emergent technologies [12] [13]. Therefore, educational institutions should consider reconstructing teacher preparation programs to focus on pre-service teachers' technological knowledge and competencies [27] to keep up with the rapid digital transformation [49].

\section{$7 \quad$ Conclusion and limitations}

This study investigated the critical factors contributing to pre-service teachers' intentions to use the IoT technology in their future teaching and learning in Saudi Arabia. Therefore, TAM-related factors, including perceived ease of use, usefulness, user attitude, and pre-service teachers' intentions to use IoT, were proposed and examined. 
We hypothesized that pre-service teachers participating in this study would develop a positive attitude toward using IoT technologies in their future profession because of their perceptions of its ease of use and usefulness, which, in turn, will contribute to raising their level of intention to use it in the future. One simple regression and two multiple linear regression analyses were conducted to identify the factors predicting participants' intentions to use the IoT. The results highlighted that pre-service teachers' perceptions of IoT usefulness are positively influenced by their perceptions of its ease of use. Both perceived usefulness and ease of use significantly influenced attitude; however, the IoT perceived ease of use had a more substantial influence than its perceived usefulness. Pre-service teachers' intentions to use the IoT in classrooms were positively and significantly affected by their perceptions of IoT usefulness. However, their intentions to use the IoT in classrooms were not significantly affected by their attitudes toward using it. In summary, the result proved that pre-service teachers' perception of IoT usefulness was the most critical determinant, followed by its perceived ease of use in predicting participants' intentions to use it in future classrooms. The findings of this study imply the need for more inclusion of IoT technologies in the design of course materials and syllabi of teacher preparation programs and that more training should be provided to pre-service teachers in the integration of IoT technology as an effective tool in teaching and learning.

Several limitations were associated with this study. First, data analysts suggest that structural equation modeling (SEM) is the most effective method of data analysis. However, SEM was not considered in this study due to the small sample size $(n=47)$ because SEM analysis requires 15-20 respondents per factor [44]. Second, for the convenience of sampling, a specific sample of pre-service teachers was selected from King Faisal University in Alahssa, in the Eastern Province of Saudi Arabia, which represents a limitation regarding the generalization of the findings. Therefore, future research may investigate a more comprehensive sample of pre-service teachers from different universities located in different provinces in Saudi Arabia. Third, the study was conducted within pre-service teachers studying a particular course (Instructional Software Design). Studies in other contexts might reveal different results. Therefore, future research should be conducted across different settings (e.g., in different colleges) to examine the robustness of the findings. Fourth, the results of this study were based on the factors of the TAM concept. That is, future research may consider examining external factors through an extended TAM, such as pre-service teachers' self-efficacy, technological competency, and institutional support. These factors might contribute to the theoretical framework of IoT technology's adoption in the teaching-learning process. Fifth, this study used a quantitative approach to collect data; thus, future research may incorporate a mixed-method approach because qualitative data will enrich the understanding of pre-service teachers' perceptions of their intention to use the IoT. Sixth, in this study, data was collected just before the official announcement by the Ministry of Education in Saudi Arabia of school closures in response to COVID-19 pandemic restrictions. The rapid shift to distance learning has dramatically affected the landscape of teaching and learning [49] [50] [51]. Accordingly, the factors affecting pre-service teachers' use of the IoT may differ given the distance learning environment. Therefore, future work may investigate these factors considering distance learning characteristics. Finally, given the importance of pre-service teachers' behavioral 
intention to use modern technologies and its impact on the actual use in the future [27], this study recommends investigating the TAM-related factors towards a number of other new technological applications such as robotics and artificial intelligence [52] among pre-service teachers.

\section{$8 \quad$ References}

[1] S. Kraijak and P. Tuwanut, "A Survey on IoT Architectures, Protocols, Applications, Security, Privacy, Real-world Implementation, and Future Trends," in $11^{\text {th }}$ International Conference on Wireless Communications, Networking and Mobile Computing (WiCOM), Shanghai, IET, September 21-23, 2015, pp. 1-6. https://doi.org/10.1049/cp.2015.0714

[2] G. Reggio, M. Leotta, M. Cerioli, R. Spalazzese, and F. Alkhabbas, "What Are IoT Systems for Real? An Experts' Survey on Software Engineering Aspects," Internet of Things, 12, 2020. https://doi.org/10.1016/j.iot.2020.100313

[3] M. B. Abbasy and E. V. Quesada, "Predictable Influence of IoT (Internet of Things)," The Higher Education, International Journal of Information and Education Technology, vol. 7, no. 12, 2017, pp. 914-920. https://doi.org/10.18178/ijiet.2017.7.12.995

[4] M. Abdel-Basset, G. Manogaran, A. Gamal, and V. Chang, "A Novel Intelligent Medical Decision Support Model Based on Soft Computing and IoT," IEEE Internet of Things Journal, vol. 7, no. 5, 2019, pp. 4160-4170. https://doi.org/10.1109/JIOT.2019.2931647

[5] M. Ammar, G. Russello, and B. Crispo, "Internet of Things: A Survey on the Security of IoT Frameworks," Journal of Information Security and Applications, vol. 38, 2018, pp. 8-27. https://doi.org/10.1016/j.jisa.2017.11.002

[6] P. Mertala, "Young Children's Perceptions of Ubiquitous Computing and the Internet of Things," British Journal of Educational Technology, vol. 51, no. 1, 2020, pp. 84-102. https://doi.org/10.1111/bjet.12821

[7] Statista, "Internet of Things (IoT) connected devices installed base worldwide from 2015 to 2025," Statista, 2021. Accessed on: Sept. 9, 2021. [Online]. Available: https://www.statista. com/statistics/471264/iot-number-of-connected-devices-worldwide

[8] J. Marquez, J. Villanueva, Z. Solarte, and A. Garcia, "IoT in Education: Integration of Objects with Virtual Academic Communities," in New Advances in Information Systems and Technologies, A. Rocha, A. Correia, H. Adeli, L. P. Reis, and M. M. Teixeira, (Eds.), Switzerland, Springer-Verlag, 2016, pp. 201-212. https://doi.org/10.1007/978-3-319-31232-3_19

[9] P. Putjorn, P. Siriaraya, F. Deravi, and C. S. Ang, "Investigating the Use of Sensor-Based IoT to Facilitate Learning for Children in Rural Thailand," PloS one, vol. 13, no. 8, 2018, pp. 1-23. https://doi.org/10.1371/journal.pone.0201875

[10] M. Al-Emran, S. I. Malik, and M. N. Al-Kabi, "A Survey of Internet of Things (IoT) in Education: Opportunities and Challenges," in Toward Social Internet of Things (SIoT): Enabling Technologies, Architectures and Applications, A. Hassanien, R. Bhatnagar, N. Khalifa, and M. Taha, (Eds.), Switzerland, Springer, 2020, pp. 197-209. https://doi. org/10.1007/978-3-030-24513-9 12

[11] A. Majeed and M. Ali, "How Internet-of-Things (IoT) Making the University Campuses Smart? QA Higher Education (QAHE) Perspective," in 2018 IEEE $8^{\text {th }}$ Annual Computing and Communication Workshop and Conference (CCWC), Las Vegas, IEEE, January 8-10, 2018, pp. 646-648. https://doi.org/10.1109/CCWC.2018.8301774

[12] S. Papadakis, J. Vaiopoulou, E. Sifaki, D. Stamovlasis, and M. Kalogiannakis, "Attitudes towards the Use of Educational Robotics: Exploring Pre-Service and In-Service Early Childhood Teacher Profiles," Education Sciences, vol. 11, no. 5, 2021, pp. 1-14. https://doi. org/10.3390/educsci11050204 
[13] J. E. Casey, L. K. Pennington, and S. V. Mireles, “Technology Acceptance Model: Assessing Pre-Service Teachers' Acceptance of Floor-Robots as a useful Pedagogical Tool," Technology, Knowledge and Learning, vol. 26, 2020, pp. 499-514. https://doi.org/10.1007/ $\underline{\text { s10758-020-09452-8 }}$

[14] R. Nurdin, A. Hufad, D. Tarsidi, and I. D. Aprilia, "The Effect of Internet of Things Implementation on Inclusive Practices in High School," in $2^{\text {nd }}$ International Conference on Educational Sciences (ICES), Bandung, Indonesia: Atlantis Press, October 9, 2018, pp. 149-151.

[15] M. Abdel-Basset, G. Manogaran, M. Mohamed, and E. Rushdy, "Internet of Things in Smart Education Environment: Supportive Framework in the Decision-Making Process," Concurrency and Computation: Practice and Experience, vol. 31, no. 10, 2019, pp. 1-12. https:// doi.org/10.1002/cpe.4515

[16] J. Gómez, J. F. Huete, O. Hoyos, L. Perez, and D. Grigori, "Interaction System Based on Internet of Things as Support for Education," Procedia Computer Science, vol. 21, 2013, pp. 132-139. https://doi.org/10.1016/j.procs.2013.09.019

[17] Y. Yang and K. Yu, "Construction of Distance Education Classroom in Architecture Specialty Based on Internet of Things Technology," International Journal of Emerging Technologies in Learning, vol. 11, no. 5, 2016, pp. 56-62. https://doi.org/10.3991/ijet.v11i05.5695

[18] P. Tan, H. Wu, P. Li, and H. Xu, "Teaching Management System with Applications of RFID and IoT Technology," Education Sciences, vol. 8, no. 1, 2018, p. 26. https://doi.org/10.3390/ educsci8010026

[19] V. Shapovalov, Y. Shapovalov, Z. Bilyk, A. Megalinska, and I. Muzyka, "The Google Lens Analyzing Quality: An Analysis of the Possibility to Use in the Educational Process," in Proceedings of the $2^{\text {nd }}$ International Workshop on Augmented Reality in Education, Kryvyi Rih, Ukraine, March 22, 2019. https://doi.org/10.31812/educdim.v53i1.3844

[20] M. M. Yunus, A. Suliman, L. S. Huei, T. F. Kai, and S. Kiew, "The Use of Voca-Lens to Enhance the Students Vocabulary Repertoire," International Journal of English Language and Literature Studies, vol. 9, no. 3, 2020, pp. 172-184. https://doi.org/10.18488/ journal.23.2020.93.172.184

[21] S. B. Metwali and A. A. Mabrook, "Enrichment Activities in the Home Economy based on the Internet of Things and Inter-Studies to Develop Innovative Quality and the Future Perspective for Primary School Pupils," Journal of Research in the Fields of Quality Education, 2020, vol. 6, no. 30, pp. 185-284.

[22] W. Y. Ibraheem and R. A. Shorab, "Internet of Things Technology: Concept and Educational Applications," Educational Technology: Egyptian Association for Educational Technology, vol. 30, no. 10, 2020, pp. 3-13.

[23] N. S. Kew, T. W. Koh, Z. Tasir, N. F. Jumaat, and N. D. Abd Halim, "A Systematic Review on Internet of Things in Language Practice," in IOP Conference Series: Materials Science and Engineering, IOP Publishing, vol. 1051, no. 1, February 2021, pp. 1-8. https://doi. org/10.1088/1757-899X/1051/1/012009

[24] S. D. D'Cunha, "Saudi Arabia's Prince Bids for Global Tech Leadership, but there are Major Hurdles on the Way," Forbes, 2018. Accessed on: Sept. 9, 2021. [Online]. Available: https:// www.forbes.com/sites/suparnadutt/2018/05/21/saudi-arabias-prince-bids-for-global-techleadership-but-there-are-major-hurdles-on-the-way/\#486415045eca

[25] A. M. Al-Abdullatif and M. S. Alsaeed, "Evaluating Visible Learning: Mathematics Teachers' Practices in Technology-Enhanced Classrooms," Cogent Education, vol. 6, no. 1, 2019, pp. 1-24. https://doi.org/10.1080/2331186X.2019.1686798

[26] Education and Training Evaluation Commission. Accessed on: Sept. 9, 2021. [Online]. Available: https://www.eec.gov.sa 
[27] A. M. Al-Abdullatif, "Auditing the TPACK Confidence of Pre-Service Teachers: The Case of Saudi Arabia," Education and Information Technologies, vol. 24, no. 6, 2019, pp. 33933413. https://doi.org/10.1007/s10639-019-09924-0

[28] O. V. Strutynska, G. M. Torbin, M. A. Umryk, and R. M. Vernydub, "Digitalization of the Educational Process for the Training of the Pre-Service Teachers," in CTE 2020: $8^{\text {th }}$ Workshop on Cloud Technologies in Education, Kryvyi Rih, Ukraine, December 18, 2020.

[29] A. I. Attwood, "Changing Social Learning Theory Through Reliance on the Internet of Things and Artificial Intelligence," Journal of Social Change, vol. 12, no. 1, 2020, p. 103-111. https://doi.org/10.5590/JOSC.2020.12.1.08

[30] R. H. Abdulmajeed, "Effectiveness of a Proposed Program in Light of Fourth Industrial Revolution Requirements Using a Smart Learning Environment Based on Internet of Things for Developing Digital Teaching Skills, Envisioning the Future and Technological Acceptance for Female Mathematics Prospective Teachers," Journal of Mathematics Education, vol. 24, no. 1, 2021, pp. 182-271. https://doi.org/10.21608/armin.2021.143152

[31] A. Jean-Charles, "Internet of Things in Education: Artificial Intelligence Voice Assistant in the Classroom," in Society for Information Technology \& Teacher Education International Conference, Washington DC, Association for the Advancement of Computing in Education (AACE), March 26, 2018.

[32] Y. Hala and A. N. Arifin, "Improving Teachers' Competence on the Use of Internet of Things for Teachers in the City of Makassar," Journal of Community Service and Empowerment, vol. 1, no. 3, 2020, pp. 156-161. https://doi.org/10.22219/jcse.v1i3.12420

[33] F. D. Davis, "Perceived Usefulness, Perceived Ease of Use, and User Acceptance of Information Technology," MIS Quarterly, 1989, pp. 319-340. https://doi.org/10.2307/249008

[34] F. Weng, R. J. Yang, H. J. Hos, and H. M. Su, "A TAM-Based Study of the Attitude Towards Use Intention of Multimedia Among School Teachers," Applied System Innovation, vol. 1, no. 3, 2018, pp. 1-9. https://doi.org/10.3390/asi1030036

[35] A. Aljaloud, W. Billingsley, and P. Kwan, "Factors That Influence Teachers' Decisions to Use Smartphone Clicker Apps to Enhance Teacher-Student Interactions in University Classrooms in Saudi Arabia," Learning: Research and Practice, vol. 5, no. 1, 2019, pp. 67-86. https://doi.org/10.1080/23735082.2018.1459802

[36] D. Y. Lee and M. R. Lehto, "User Acceptance of YouTube for Procedural Learning: An Extension of the Technology Acceptance Model," Computers \& Education, vol. 61, 2013, pp. 193-208. https://doi.org/10.1016/j.compedu.2012.10.001

[37] W. M. Al-Rahmi, M. S. Othman, and L. M. Yusuf, "Effect of Engagement and Collaborative Learning on Satisfaction Through the Use of Social Media on Malaysian Higher Education," Research Journal of Applied Sciences, Engineering and Technology, vol. 9, no. 12, 2015, pp. 1132-1142. https://doi.org/10.19026/rjaset.9.2608

[38] N. Marangunić and A. Granić, "Technology Acceptance Model: A Literature Review from 1986 to 2013," Universal Access in the Information Society, vol. 14, no. 1, 2015, pp. 81-95. https://doi.org/10.1007/s10209-014-0348-1

[39] T. Teo, X. Fan, and J. Du, "Technology Acceptance Among Pre-Service Teachers: Does Gender Matter?" Australasian Journal of Educational Technology, vol. 31, no. 3, 2015, pp. 235-251. https://doi.org/10.14742/ajet.1672

[40] S. Y. Park, "An Analysis of the Technology Acceptance Model in Understanding University Students' Behavioral Intention to Use E-Learning," Journal of Educational Technology \& Society, vol. 12, no. 3, 2009, pp. 150-162.

[41] W. J. Doll and G. Torkzadeh, "Developing a Multidimensional Measure of System Use in an Organizational Context," Information \& Management, vol. 33, no. 4, 1998, pp. 171-85. https://doi.org/10.1016/S0378-7206(98)00028-7 
[42] L. Cohen, L. Manion, and K. Morrison, Research Methods in Education, 5th ed., London, UK: Routledge Falmer, 2000.

[43] A. Field, Discovering Statistics Using IBM SPSS Statistics. London, UK: SAGE Publications, 2013.

[44] E. A. Hassan, Psychological and Educational Statistics: Applications Using PSS18 Program. Cairo, Egypt: Dar Al-Fikr Al-Arabi, 2016.

[45] Y. M. Huang, "The Factors that Predispose Students to Continuously Use Cloud Services: Social and Technological Perspectives," Computers \& Education, vol. 97, 2016, pp. 86-96. https://doi.org/10.1016/j.compedu.2016.02.016

[46] A. M. Al-Abdullatif and A. A. Gameil, "The Effect of Digital Technology Integration on Students' Academic Performance through Project-Based Learning in an E-Learning Environment," International Journal of Emerging Technologies in Learning, vol. 16, no. 11, 2021, pp. 189-210. https://doi.org/10.3991/ijet.v16i11.19421

[47] F. D. Davis, R. P. Bagozzi, and P. R. Warshaw, "User Acceptance of Computer Technology: A Comparison of Two Theoretical Models," Management Science, vol. 35, 1989, pp. 982-1002. https://doi.org/10.1287/mnsc.35.8.982

[48] D. D. Ramlowat and B. K. Pattanayak, "Exploring the Internet of Things (IoT) in Education: A review," Information Systems Design and Intelligent Applications, 2019, pp. 245-255. https://doi.org/10.1007/978-981-13-3338-5 23

[49] T. Karakose, H. Polat, and S. Papadakis, "Examining Teachers' Perspectives on School Principals' Digital Leadership Roles and Technology Capabilities during the COVID-19 Pandemic," Sustainability, vol. 13, no. 23, 2021, pp. 1-20. https://doi.org/10.3390/ $\underline{\text { su132313448 }}$

[50] T. Karakose, R. Yirci, and S. Papadakis, "Exploring the Interrelationship between Covid-19 Phobia, Work-Family Conflict, Family-Work Conflict, and Life Satisfaction among School Administrators for Advancing Sustainable Management," Sustainability, vol. 13, no. 15, 2021, pp. 1-19. https://doi.org/10.3390/su13158654

[51] T. Karakose, R. Yirci, S. Papadakis, T. Y. Ozdemir, M. Demirkol, and H. Polat, "Science Mapping of the Global Knowledge Base on Management, Leadership, and Administration Related to COVID-19 for Promoting the Sustainability of Scientific Research," Sustainability, vol. 13, no. 17, 2021, pp. 1-22. https://doi.org/10.3390/su13179631

[52] S. Papadakis, "Robots and Robotics Kits for Early Childhood and First School Age," International Journal of Interactive Mobile Technologies, vol. 14, no. 18, 2020, pp. 34-56. https://doi.org/10.3991/ijim.v14i18.16631

\section{Authors}

Ahlam Mohammed Al-Abdullatif is an associate professor with the Curriculum and Instruction Department, King Faisal University, Saudi Arabia. She is an active professor and a researcher, who published with well-known publishers, such as Taylor \& Francis, Cogent, Springer, SAGE, Elsevier and IEEE. Her research interest includes the area of e-Learning, particularly on how information and Communication Technology (ICT) enhances teaching and learning practices. She won the 2017/2018 Faculty Excellence Award at King Faisal University and the 2017/2018 E-learning Excellence Award from the National Centre of E-learning, Saudi Arabia.

Amany Ahmed Al-Dokhny is an Egyptian associate professor, with the Instructional Technology Department, Faculty of Specific Education at Ain Shams University in Egypt, as well as Faculty of Education at King Faisal University in Saudi Arabia. Her 
areas of interest are e-learning, LMS, infographic, social networks, augmented reality, the internet of things, and assistive technology for disabilities. She has participated in various international academic projects, she has 16 years of experience with Saudi and Egyptian teaching settings, adviser to the National Center for Measurement in the KSA, and an external reviewer for the scientific journal and scientific books at the Center of Translation at KSU. An external reviewer at $\mathrm{UOH}$ at KSA, and Kuwait University at Kuwait. (amany.eldokhny@sedu.asu.edu.eg).

Amr Mohammed Drwish is an Egyptian associate professor with the Instructional Technology Department, Faculty of Education at King Faisal University in Saudi Arabia. His areas of interest are e-learning, scaffolding learning, infographic, social networks, augmented reality, and web quest. He is an adviser to the National Center for Measurement in the KSA, an internal reviewer at the scientific journal of KFU, and an external reviewer at UOH, JU, and UOB at KSA. Program accreditation advisor for postgraduate programs at the faculty of Education, KFU. Member of the Educational Consulting Unit, College of Education, KFU. (amr_darwish@edu.helwan.edu.eg).

Article submitted 2021-09-19. Resubmitted 2021-10-26. Final acceptance 2021-12-26. Final version published as submitted by the authors. 